\title{
VENTRICULAR FIBRILLATION IN A PATIENT WITH UNSUSPECTED MITRAL VALVE PROLAPSE AND A PROLONGED Q-T INTERVAL
}

\author{
R.B. FORBES \& G.H. MORTON
}

THE CLICK-MURMUR SYNDROME of mitral valve prolapse and a prolonged Q-T interval have both been associated with cardiac arrhythmias and sudden death. ${ }^{1-6}$ The precise incidence, pathogenesis and prognosis of these disorders remains uncertain; however, the following case report strongly suggests that patients with clinical signs of mitral valve prolapse require recognition and investigation prior to anaesthesia and surgary.

\section{CASE REPORT}

A 25 -year-old woman weighing $68 \mathrm{~kg}$ was admitted from the Emergency Department with a diagnosis of acute appendicitis. She had previously undergone uneventful general anaesthetics for a dental extraction and a therapeutic abortion. She was taking no medications and denied drug allergies.

Physical examination revealed in early systolic murmur and marked tenderness in the right lower quadrant, but was otherwise unremarkable. Haemoglobin, blood urea nitrogen, electrolytes and creatinine were normal. She was transferred to the operating room on the evening of admission for an emergency appendectomy.

On arrival her blood pressure was $110 / 60 \mathrm{~mm}$ $\mathrm{Hg}$, pulse $80 /$ minute and electrocardiography revealed sinus rhythm. An intravenous catheter was inserted. Following pre-oxygenation, anaesthesia was induced with thiopentone 350 mg.; cricoid pressure was applied and intubation with a $8 \mathrm{~mm}$ cuffed tracheal tube was facilitated with succinylcholine $100 \mathrm{mg}$.

Immediately following intubation ventricular fibrillation was seen on the electrocardiograph monitor. The patient was not cyanosed but the pulse was not palpable. The precordium was thumped, 100 per cent oxygen was administered and external cardiac massage was started. Conversion to sinus thythm was almost immediate and a palpable pulse returned; but frequent mul-

R.B. Forbes, M.D., Resident, Department of Anaesthesia; G.H. Morton. M.D.. F.R.C.P.(C). Staff Anaesthetist, Department of Anaesthesia, University of Alberta Hospital, Edmonton. Alberta.

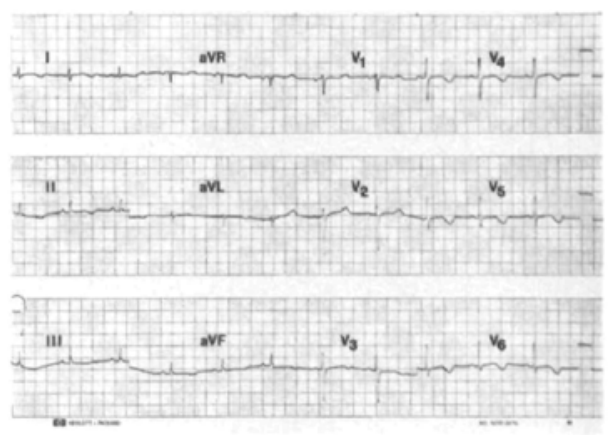

Figure I E.C.G. shows non-specific T-wave changes and $T$ wave inversion in I. II, III, aVF, and $\mathrm{V}_{4-6} \mathrm{Q}-\mathrm{T}_{\mathrm{c}}$ interval is 0.47 seconds. (Normal 0.43-0.44 seconds.)

tifocal premature ventricular contractions continued. Lidocaine $100 \mathrm{mg}$ intravenously decreased the frequency of the premature beats. At this point the operation was postponed. The patient was allowed to regain consciousness and then was transferred to the coronary care unit for further assessment.

Detailed questioning elicited only a vague history of dyspnoea on exertion. There was no family history of cardiac disease. Physical examination revealed cardiac size to be normal, a grade II/VI early systolic murmur audible along the left sternal border and a late systolic click. There were no enzyme or electrolyte abnormalities.

Electrocardiography revealed a consistently long $Q-T_{c}$ interval of 0.47 seconds and variable T-wave changes (Figure 1). The phonocardiogram showed the variable late systolic clicks which were audible on auscultation (Figure 2). A subsequent echocardiogram showed the classical appearance of late systolic prolapse of the posterior leaflet of the mitral valve (Figure 3 ).

The following day the patient was rescheduled for operation. Preoperatively she received propranolol $2 \mathrm{mg}$ intravenously and a lidocaine infusion was started a rate of $1.0 \mathrm{mg}$ per minute and continued throughout the operative procedure. Adequate preanaesthetic sedation was achieved with intramuscular morphine $10 \mathrm{mg}$. 


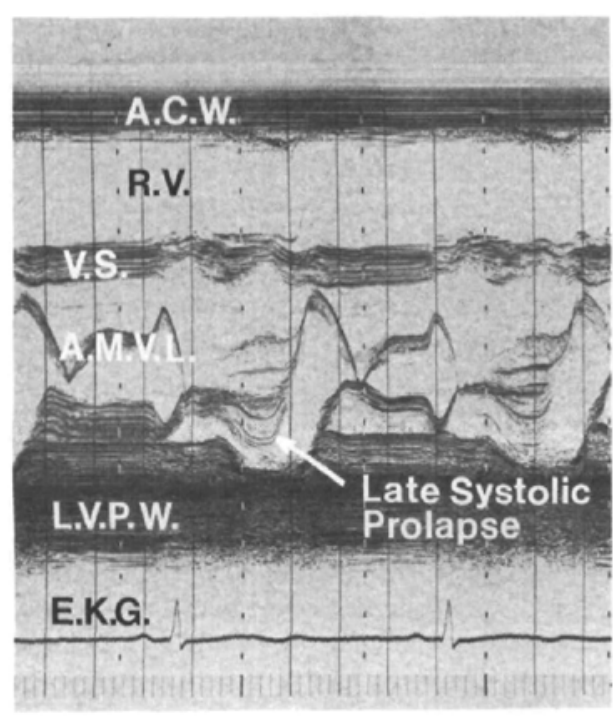

Figure 2 Echocardiogram showing late systolic prolapse of posterior mitral valve leafiet. (A.C.W. = Anterior chest wall, R.V. = Right ventricle, V.S. $=$ Ventricular septum, A.M.V.L. = Anterior mitral valve leaflet, L.V.P.W. = Left ventricular posterior wall.)

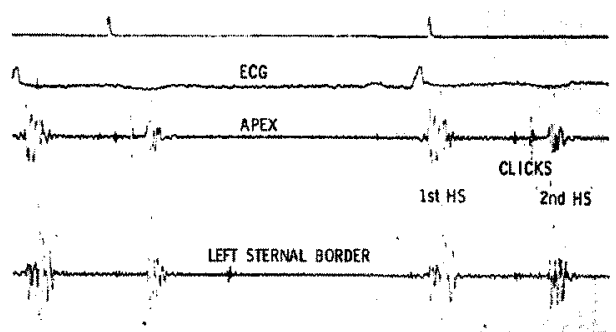

Figure 3 Phonocardiogram showing late systolic clicks.

On this occasion anaesthesia was induced with diazepam $5 \mathrm{mg}$ and thiopentone $50 \mathrm{mg}$ intravenously, followed by succinylcholine $60 \mathrm{mg}$. Tracheal intubation was uneventful. Anaesthesia was maintained with a mixture of nitrous oxide and oxygen supplemented with Innovar ${ }^{\star} 0.5 \mathrm{ml}$ and fentanyl $75 \mu \mathrm{g}$. Neuromuscular blockade was achieved with a continuous infusion of succinylcholine 0.1 per cent. The operation proceeded uneventfully and a gangrenous appendix was removed. The patient's condition remained stable throughout the postoperative period, except for occasional premature ventricular contractions. The lidocaine was continued for 24 hours, then replaced with propranolol $20 \mathrm{mg}$. q.i.d. After nine days in hospital the patient was discharged in good condition on propranolol.

\section{Discussion}

Mitral valve prolapse can occur at any age, but is most commonly diagnosed in patients between 20 and 60 years of age. ${ }^{7}$ The majority of patients are female ${ }^{8}$ and a family history of cardiac disease may or may not be present ${ }^{8.9}$ The prevalence of mitral valve prolapse is presently unknown; however, echocardiographic examination of healthy young females revealed mitral prolapse in over six per cent of the population studied. ${ }^{10.11}$ This suggests that mitral prolapse may be a common cardiac abnormality.

Many patients with this disorder are asymptomatic; however, others will complain of fatigue or dyspnoea. ${ }^{8}$ Palpitations have been noted in up to 50 per cent of patients with mitral prolapse 6 and long-term monitoring has substantiated the frequent occurrence of arrhythmias. ${ }^{2,8.12}$ Chest pain may also be present $t^{8,13}$ and varies from mild to incapacitating.

Physical examination may reveal abnormalities of the bony thorax such as "straightback", pectus excavatum, or scoliosis, which occur frequently enough to be considered part of the syndrome. ${ }^{14}$ The characteristic findings on auscultation are a variable systolic click followed by a systolic murmur. The click may occur in early, mid or late systole or be intermittently absent. The murmur, if absent, may be elicited by examining the patient in the left decubitis position, sitting, standing, or leaning forward. These postural changes may also cause the click to occur earlier in systole. Careful, repeated examination, making use of all the postural changes may be required to make an accurate diagnosis.

Up to half the patients with mitral valve prolapse display abnormalities on electrocardiography. ${ }^{2.8 .13}$ The most common pattern consists of flattening or inversion of T-waves on Leads II. III and aVF. Similar changes may also be seen in the precordial leads, as well as a wide variety of less frequent abnormalities.

Arrhythmias are a frequent feature of mitral valve prolapse. $2,3,8.12$ Premature ventricular contractions are the most common abnormality but supraventricular tachycardia, atrial fibrillation or flutter and ventricular tachycardia or fibrillation may also be seen.

Conduction defects are observed less frequently and the abnormalities include $1^{\circ} \mathrm{A} . \mathrm{V}$. 
block, left and right bundle branch blocks, ${ }^{8}$ sinus bradycardia with sinus arrest' and complete atrio-ventricular block. ${ }^{4}$

Prolongation of the Q-T interval, as was dis. played by the patient presented. is an infrequent occurrence in association with the prolapsing mitral valve syndrome; ${ }^{7.13}$ however, it has been reported in one case of sudden death during emotional stress in a patient with mid-systolic clickmurmur syndrome. ${ }^{6}$

Echocardiography provides a non-invasive technique for demonstrating mitral valve prolapse and has been shown to correlate with the clinical diagnosis in over 80 per cent of cases."

The most important complications associated with this syndrome are spontaneous rupture of the chordae tendinae, progressive mitral regurgitation. infective endocarditis and sudden death.

\section{Andesthetic considerations}

In view of the evidence that mitral valve prolapse occurs in over six per cent of apparently healthy females ${ }^{10.11}$ a high index of suspicion should be maintained when a patient with signs or symptoms suggestive of this disorder presents for anaesthesia.

The optimal anaesthetic management of a patient with mitral valve prolapse requires consideration of the haemodynamic changes precipitated by the induction and maintenance of anaesthesia. Pharmacological intervention or changes in posture that cause tachycardia. sudden reductions in peripheral vascular resistance. or reduction in venous return and left ventricular end diastolic volume enhance leaflet redundancy and increase valve prolapse. With the resultant fall in cardiac output and coronary perfusion arrhythmias may be precipitated. Therefore, during anaesthesia, maintenance of the end diastolic ventricular volume by avoiding tachycardia, increased intrathoracic pressure, vena caval compression or marked falls in peripheral vascular resistance. are of primary importance. Preoperative treatment with propranolol and lidocaine may also aid in the avoidance of arrhythmias.

In this particular patient the situation was complicated by the presence of a prolonged $Q-T$ interval which, by itself, has been associated with ventricular fibrillation and sudden death. ${ }^{5}$ The aetiology of this disorder is also unknown, but it has been related to an imbalance in sympathetic tone altering ventricular repolarization. The anaesthetic management of patients with the prolonged $Q-T$ interval has been thoroughly considered in two recent reviews. ${ }^{15.16}$ and will not be discussed further here. It is not possible to determine whether the episode of fibrillation in this patient was the result of haemodynamic changes affecting mitral valve function or pre-existing Q-T abnormalities. However, a high index of suspicion on discovery of the systolic murmur and click during the preoperative clinical examination should have led to a more thorough preoperative assessment and might have prevented the anaesthetic complication described.

\section{Summary}

Mitral valve prolapse is a common cardiac abnormality associated with arrhythmias and sudden death. In most instances it can be diagnosed on the basis of physical findings. Those patients who are symptomatic or who display electrocardiographic abnormalities appear to be most susceptible to arrhythmias and, therefore, may be at increased risk for anaesthesia. Because the syndrome is relatively common and may present a very innocent clinical picture, anaesthetists should be aware of this condition and the problems it may present.

A case of mitral valve prolapse syndrome associated with ventricular fibrillation on induction of anaesthesia is reported. The symptoms and pathophysiology of the disorder are reviewed and the potential problems and the anaesthetic management are discussed.

\section{RÉSUMÉ}

Le prolapsus de la valve mitrale est une anomalie fréquente et donne lieu à des ary thmies dont certaines peuvent causer des morts subites. Le diagnostic peut le plus souvent ètre fait à partir de l'examen physique du malade. Lorsque cette anomalie est retrouvée chez des sujets symptomatiques ou qu'elle est associée à des anomalies électrocardiographiques, le risque d'arythmie est plus grand et le risque anesthésique plus élevé. Ce syndrome étant relativement commun et se traduisant fréquemment par une image clinique d'apparence bénigne, les anesthésistes devraient ètre conscients des problèmes qu'il peut créer.

Les auteurs rapportent le cas d'une jeune femme porteuse d'un prolapsus mitral et qui a présenté une fibrillation ventriculaire (reconnue et traitée sans séquelles) lors de l'induction d'une anesthésie. Ils présentent une revue de la physiopathologie et de la symptomatologie de cette affection, ainsi que les implications anesthésiques pertinentes. 


\section{ACKNOWLEDGEMENT}

The authors would like to thank Dr. M. Haraphongse, Division of Cardiology, Univer. sity of Alberta Hospital. for his assistance in preparing this case report.

\section{REFERENCES}

1. Leichtman, D. Nelson, R.,Gobel, F.l...AlexANDER, B.S. \& COHN, J.N. Bradycardia with mitral valve prolapse. Ann. Intern. Med. 85: 453 (1976).

2. CAMPBell, R.W.F., Godman, M.G., Fiddier, G.I.. Marquis, R.M. \& JuLIAN, D.G. Ventricular arrhythmias in syndrome of balloon deformity of mitral valve. Br. Heart J. 38: 1053 (1976).

3. Ritchie, J.L., Hammermeister, K.E. \& KenNEDY, J.W. Refiactory ventricular tachycardia and fibrillation in a patient with the prolapsing mitral leaftet syndrome: successful control with overdrive pacing. Am. J. Card. 37: 314 (1976).

4. Woodley, D., Chambers. W.. Starke, H. Dzindzio, B. \& Forker. A.D. Intermittent complete atrioventricular block masquerading as epilepsy in the mitral valve prolapse syndrome. Chest 72: 369 (1977).

5. Schwartz. P.J. Periti, M. \& Malliani. A. The long Q-T syndrome. Am. Heart J. 89; 378 (1975).

6. Shappell. S.D., Marshall. C.E., Brown, R.E. $\&$ BRUCE. T.A. Sudden death and the familial occurrence of mid-systolic click, late systolic murmur syndrome. Circulation 48 : 1128 (1973).
7. Devereux. R.B.. Perloff, J.K.. Reichtik. N.\& JosephSON. M.B. Mitral valve prolapse. Circulation 54:3(1976).

8. JERESATY. R.M. Mitral valve prolapse-click syn. drome. Prog. Cardiovasc. Dis. 15:623 (1973).

9. Allen. H. Harris, a. Leatham. A. Significance and prognosis of an isolated late systolic murmur: a 9-to 22-year follow-up. Br. Heart J. 36: 525 (1974).

10. Brown. O.R., Kloster. F.E. \& De Mots. H. Incidence of mitral valve prolapse in the asymptomatic normal. Circulation 52 (Supple. II): 77 (1975).

11. Procacci, P.M. Savran, S.V.. Schreiter. S.L. \& BRYSON. A.L. Prevalence of elinical mitralvalve prolapse in 1, 169 young women. N. Eng. J. Med. 294: 1086 (1976)

12. WINKLE, R.A., Lopes, M.G. \& FitzGerald. J.W. Arrhythmias in patients with valve prolapse. Circulation 52: 73 (1975).

13. Barlow, J.B. \& Pocock, W.A. The problem of noninjection systolic clicks and associated mitral systolic murmurs: emphasis on the billowing mitral leaflet syndrome. Am. Heart J. 90:636 (1975).

14. Bon Tempo, C.P., Ronan, J.A., De Leon, A.C. \& Twige, H.L. Radiographic appearance of the thorax in systolic click-late systolic murmur syndrome. Am. D. Cardiology 36:27 (1975).

15. Callaghan. M.l.. Nichols. A.B. \& Sweet. R.B. Anesthetic management of prolonged Q-T interval syndrome. Anesthesiology 47: 67 (1977).

16. OWitz, S., Partilas, V., Pratila, MargaretG. \& DIMICH, IVAN. Anaesthetic considerations in the prolonged Q.T interval (LQTS): A case report. Canad. Anaesth. Soc. J. 26:50 (1979). 